\title{
Cardiac pacing: the service should be local as the anaesthetic
}

A decade ago attention was drawn to the low rate of pacemaker implantation in the United Kingdom. The limited availability of pacemaker services in district general hospitals (DGHs) was identified as a contributing factor. ${ }^{1}$ Five years later the pacing rate in the United Kingdom had increased to $148 \mathrm{implants/million/year,} \mathrm{but}$ this was only $27-41 \%$ of the rates in some other countries. ${ }^{2}$ By 1992 the rate was 202/million/year ${ }^{3}$ but less than a third of hospitals implanted pacemakers. ${ }^{4}$ The recent British Cardiac Society report on cardiology in district hospitals acknowledges the role of district hospitals in providing pacemaker services. ${ }^{4}$

This role is underlined by two reports from district hospitals. Doherty et al reviewed their experience of providing a pacemaker service in a Scottish district hospital remote from a regional centre, and showed that permanent cardiac pacing, including dual chamber pacing, can be carried out safely and effectively in this setting. ${ }^{5}$ Dual chamber pacing is more expensive and more time-consuming than VVI pacing. The relative cost effectiveness of these two pacing modes has been questioned ${ }^{6}$ and is to be investigated in a multicentre study, ${ }^{7}$ the results of which may have important cost and workload implications for all pacing centres. On pages 76-79 Ibrahim et al draw attention to the clinical benefits of DDD pacing in the absence of sustained atrial arrhythmia and provide important evidence that most patients paced in DDD mode continue to use it in the long term. ${ }^{8}$

\section{Advantages of a local service}

There are clinical, social, and economic reasons for providing cardiac pacing in district hospitals, particularly if there is no large cardiac centre nearby. Most patients requiring pacing are elderly and averse to long hospital stays and transfer to distant hospitals. Some patients have refused pacing because it involved inter-hospital transfer. A local service avoids the cost of ambulance transfers and escorts during transfer, shortens hospital stays, and makes more efficient use of hospital beds. Up to $65 \%$ of patients needing permanent pacing present as emergency medical admissions. ${ }^{9}$ Patients may wait several days in a district hospital for transfer to a regional pacing centre, exposing them to the additional risks of temporary pacing-for example, of septicaemia. ${ }^{10}$

Local expertise in pacemaker management is invaluable. If a problem with a pacemaker is suspected, the patient and general practitioner need prompt access to expert local advice. This local expertise can also be used to encourage referral of appropriate patients for pacing, through clinical communication with general practitioners, postgraduate educational activity, or through agreed referral guidelines.

Equipment requirements

A pacing service requires little capital expenditure. A dedicated pacing room is desirable but not essential and it is perfectly feasible to implant pacemakers in a general $x$ ray department ${ }^{9}$ or operating theatre. ${ }^{5}$ Apart from the pacemaker/analyser, the equipment needed during implantation should be available in any hospital.

Investigational facilities to identify patients who need pacemakers and to assess subsequent problems should be available in district hospitals. These facilities include ambulatory electrocardiography, exercise testing, and tilt testing. Pacemaker follow up requires programmers, usually provided by manufacturers with the purchase of pacemakers. Pacing centres need a range of analyser/programmers to check and adjust most commonly used pacemakers. Most centres implant pacemakers from several manufacturers to ensure familiarity with different pacemakers and availability of programmers. This policy also limits the potential workload and economic consequences should a technical fault necessitate explantation and replacement of any model of pacemaker in large numbers.

\section{Staffing and training}

Adequate staffing is essential for the safe provision of a pacing service. Every district hospital should have at least one cardiologist, together with supporting staff, including technicians. ${ }^{4}$ There are still some hospitals with no cardiologist, ${ }^{11}$ and some DGH cardiologists may not have had training or recent experience in pacing. Most district hospital cardiologists have a commitment in general medicine and a large investigational workload, and a pacing service places additional demands on their time. In hospitals with only one cardiologist the pacing service may be without experienced medical cover when the cardiologist is on leave. This underlines the importance of experienced cardiology technicians. Sometimes patients have to be referred to another centre, but this is rarely required. ${ }^{9}$

Experience in pacemaker selection and implantation and in complications of pacing is an essential part of training in cardiology, and only doctors with such experience (and cardiologists in training) should undertake this work. Pacemaker complications are more frequent when the operator is inexperienced..$^{12}$ If pacing in district hospitals is carried out by experienced operators, complication rates should be low. It might be argued that devolution of permanent pacing to district hospitals reduces the ability of regional centres to offer training and to carry out research. If healthcare purchasers and providers achieve the recommended targets for pacemaker implantation of 300/million/year, ${ }^{4}$ there will be ample opportunity for training and for research in cardiac pacing in both regional centres and district hospitals.

\section{Finance and audit}

For many years cardiology units in the United Kingdom have struggled with inadequate budgets for pacemaker 
purchase. This should happen no longer. Clear guidelines have been published on the appropriate choice of pacemaker for different clinical situations. ${ }^{13}$ Such guidelines allow the setting of standards for provision of pacemaker services, and offer an opportunity for local, national, and international audit. The cost implication of implementing these guidelines has been examined, ${ }^{14} 15$ enabling purchasers to calculate the amount that they need to spend on cardiac pacing. Cardiac pacing will compete with other demands on resources, and local cardiologists have an important role in ensuring that purchasers are aware of the standards of quality and quantity that they should be purchasing, and of the implications of failing to do so.

\section{Future developments}

It is little more than 30 years since the first use of cardiac pacing. Rapid technological progress, particularly in the past decade, has provided smaller more reliable pacemakers with longer battery life and features such as dual chamber and rate adaptive pacing as routine options. Most of these developments were not foreseen in the early days of pacing, ${ }^{16}$ so future trends must be predicted with caution. There may be some, probably unjustified, concern that smaller pacing centres may fail to keep pace with new developments. However, among hopes for the future must be the development of the "smart" pacemaker, capable of delivering appropriate pacing in various clinical situations, with a minimum need for re-programming ${ }^{17}$ and the development of a universal analyser/programmer, capable of interrogating and adjusting different pacemakers from different manufacturers. ${ }^{18}$ Such developments would facilitate the safe and effective provision of pacemaker services in district hospitals, but the crucial factor in achieving this widely and uniformly will be the provision of adequate levels of medical and technical staff in cardiology in every district hospital.

County Hospital,

Hereford HR1 2ER

DAVID PITCHER

1 Rickards AF. Where's the block? Br Med $f$ 1984;288:737-8.

2 Parsonnet V, Bernstein AD. The 1989 World Survey of Cardiac Pacing. PACE 1991;14:2073-6.

3 UK National Pacing Database. February 1994

4 A report of a working group of the British Cardiac Society: cardiology in the district hospital. Br Heart f 1994;72:303-8.

5 Doherty JG, Dawson F, Kerr F. Permanent pacemaker practice at a Scottish district general hospital between 1987 and 1993. Br Heart $\mathcal{f}$ 1995;73:475-8.

6 Petch MC. Who needs dual chamber pacing? Br Med f 1993;307:215-6.

7 Payne GE, Skehan JD. Issues in cardiac pacing: can agism be justified? Br Heart $\mathcal{f}$ 1994;72:102-3.

8 Ibrahim B, Sanderson JE, Wright B, Palmer R. Dual chamber pacing: how many patients remain in DDD mode over the long term? Br Heart f 1995;74:76-9.

9 Thomas D, Pitcher DW. Data on file: Hereford Cardiology: Annual Pacing Review.

10 Andrews R, Skehan JD. Temporary pacing: continuing failures in general medical management. Br Heart $\mathcal{F}$ 1992;68:91P

11 Chamberlain D, Parker J, Balcon R, et al. Eighth survey of staffing in cardiology in the United Kingdom 1992. Br Heart $\mathcal{f} 1994 ; 71: 492-500$.

12 Mounsey JP, Griffith MJ, Tynan M, et al. Antibiotic prophylaxis in permanent pacemaker implantation: a prospective randomised trial. Br Heart f 1994;72:339-43.

13 Report of a working party of the British Pacing and Electrophysiology Group. Recommendations for pacemaker prescription for symptomatic bradycardia. Br Heart $\mathcal{f}$ 1991;66:185-91.

14 Ray SG, Griffith MJ, Jamieson S, Bexton RS, Gold RG. Impact of the recommendations of the British Pacing and Electrophysiology Group on pacemaker prescription and on the immediate costs of pacing in the Northern Region. Br Heart $₹$ 1992;68:531-4.

15 Mounsey JP, Ray SG, Griffith MJ, Gold RG, Bexton RS. Impact of internal audit on pacemaker prescription and the immediate costs of pacing in the Northern Region: towards implementation of the recommendain the Northern Region: towards implementation of the recommenda-
tions of the British Pacing and Electrophysiology Group. Br Heart $\mathcal{F}$ tions of the British Pacing and Electrophysiology Group. Br Heart $\mathcal{F}$ 1994;71:395-8.

16 Jeffrey $\mathrm{K}$. The next step in cardiac pacing: The view from 1958. PACE 1992;15:961-7.

17 Hayes DL. The next 5 years in cardiac pacemakers: A preview. Mayo Clin Proc 1992;67:379-84.

18 Stirbys P. A challenge: Development of a universal programmer. PACE 1993;16:693-4. 
Observer bias in blood pressure studies. $f$ Hypertens 1988;6:375-80.

16 Shaper AG, Wannamethee G, Walker M. Alcohol and mortality in British men: explaining the U-shaped curve. Lancet 1988;ii: $1267-73$.

17 Shaper AG, Wannamethee G, Weatherall R. Physica activity and ischaemic heart disease in middle-aged men. Br Heart f 1991;66:384-94

18 Shaper AG, Wannamethee G, Macfarlane PW, Walker $M$ Heart rate, ischaemic heart disease and sudden cardiac death in middle-aged British men. Br Heart $\mathcal{f} 1993 ; 70$ 49-55.

19 Phillips AN, Shaper AG, Pocock SJ, Walker M. Parental death from heart disease and the risk of heart attack. Eur Heart of 1988:9.243-51.

20 Cook DG, Shaper AG, Macfarlane PW. Using the WHO (Rose) angina questionnaire in cardiovascular epidemi(Rose) angina questionnaire in cardiovascular

21 Macfarlane PW, Watts MP, Peden J, Lennox G, Lawrie TDV. Computer assisted electrocardiogram interpretation. Br 7 Clin Equip 1976;1:61-70.

22 Dunn $M$, Alexander J, de Silva R, Hildner F. Anti-thrombotic therapy in atrial fibrillation. Chest 1989;95: 118-27S.

23 Walker M, Shaper AG. Follow-up of subjects in prospective studies based in general practice. $\mathcal{F} R$ Coll Gen Pract 1984;34:365-70.

24 World Health Organisation. Proposal for the multinational monitoring of trends and determinants in cardiovascular disease (MONICA) project and protocol. Geneva: Cardiovascular Disease Unit, World Health Organisation, 1983

25 Perry IJ, Wannamethee G, Whincup PH, Shaper AG. Asymptomatic hyperglycaemia and ischaemic heart Asymptomatic hyperglycaemia and ischaemic heart

26 Perez G, Marrugat J, Sala J. Myocardial infarction in Girona, Spain: attack rate, mortality rate and 28-day case fatality in 1988. Regicor Study Group. $\mathcal{f}$ Clin case fatality in 1988. Re

27 Evans AE, Paterson CC, Mathewson Z, McCrum EE Mcllmoyle EL. Incidence, delay and survival in Belfast
MONICA project coronary event register. Prev Epid Sante Publ 1990;38:419-27.

28 Dobson AJ, Gibberd EW, Leeder SR, et al. Ischaemic heart disease in the Hunter region of New South Wales, heart disease in the Hunter region of New South Wales,

29 Beaglehole R, Bonita R, Jackson R, Stewart A, Sharpe M, Fraser GE. Trends in coronary heart disease event rates in New Zealand. Am $\mathcal{F}$ Epidemiol 1984;120:225-35.

30 Goldberg RJ, Gore JM, Gurwitz JH, et al. The impact of age on the incidence and prognosis of initial acute myocardial infarction: the Worcester heart attack study. Am Heart $\mathcal{f}$ 1989;117:543-9.

31 Goldberg RJ, Seeley D, Becker RC, et al. Impact of atria fibrillation on the in-hospital and long-term survival of patients with acute myocardial infarctior patide perspective. Am Heart $\Im$ 1990;119:996-1001.

32 Tannen RL. Diuretic induced hypokalaemia. Kidney Int 1985;28:988-1000.

33 Fagard RH. Impact of different sports and training on cardiac structure and function. Cardiol Clin 1992;10. 241-56.

34 Ferguson EW, Bernier LL, Banta GR, Schoomaker EB. Effects of exercise and conditioning on clotting and fibrinolytic activity in men. $f$ Appl Physiol 1987;62 1416-21.

35 Renaud S, Beswick AD, Fehily AM, Sharp DS, Elwood PC. Alcohol and platelet aggregation: the Caerphilly prospective heart disease study. Am $\mathcal{F}$ Clin Nutr 1992 55:1012-7.

36 Hendrichs HFG, Veenstra J, Veltshuisnte Wierik EGM Shaafsma J, Kluft C. Effect of moderate dose of alcoho with evening meal on fibrinolytic factors. BMF 1994; 308:1003-6.

37 AIMS Trial Study Group. Effect of intravenous APSAC on mortality after acute myocardial infarction: preliminary report of a placebo-controlled trial. Lancet 1988;i: $545-9$.

38 Gray D, Keating NA, Murdock J, Skene AM, Hampton JR. Impact of hospital thrombolysis policy on out-ofhospital response to

\section{NOTICES}

The 1996 Annual Meeting of the British Cardiac Society will take place at the Scottish Exhibition \& Conference Centre, Glasgow from 7 to 9 May.

The sixtieth annual meeting of the Japanese Circulation Society will take place from 19 to 21 March 1996 at the Royal Hotel, 5-3-68 Nakanoshima, Kita-ku, Osaka 530, Japan. For further information please contact Kunio Miyatake $M D$, National Cardiovascular Centre, 5-7-1 Fujishiro-dai, Suita, Osaka 565, Japan (tel: +81 6873 0707; fax: +81 6 873 0708).
Cardiac pacing: the service should be local as the anaesthetic. $D$ Pitcher

The word "as" was omitted by the printers from the title of this editorial ( $\mathrm{Br}$ Heart $\mathrm{f}$ 1995;74:7-8). The correct title is "Cardiac pacing: the service should be as local as the anaesthetic." 